\title{
Evaluation of Laparoscopic Nissen Fundoplication for Patients with Gastro Esophageal Reflux Disease Non-Responding to Medical Treatment N.M.H.Shedeed ${ }^{1}$, A.H.Abd El-Maqoued ${ }^{1}$, A.A.Salem ${ }^{2}$, E.M.Oraby ${ }^{1}$ and B.M.Darwish ${ }^{1}$ ${ }^{1}$ General Surgery, General Surgery, Dept., Faculty of Medicine, Benha Univ., Benha, Egypt \\ ${ }^{2}$ General Surgery, Dept., Faculty of Medicine, Zagazig Univ., Zagazig, Egypt E-mail:boshradarwish2020@icloud.com
}

\begin{abstract}
Background: GERD is a very common disorder and can be managed effectively in a large number of patients with combination of life style modifications and appropriate medical therapy. Managing refractory GERD, which can be seen in up to $40 \%$ of the patients receiving PPI once daily, can be challenging. The best initial approach is optimization of PPI therapy. A careful history and use of investigative tools can help identify the contributing factors for PPI failure. Management of patients with GERD who are not responding to medical treatment represents a clinical dilemma. Laparoscopic anti-reflux surgery, especially Nissen fundoplication, is validated for management of PPI-responsive patients. However, the role of LNF for management of poor responders to PPI is controversial. Some authors advocate LNF as a proper treatment for patients with refractory GERD. Other reports considered response to medical treatment as a predictor of surgical success. GERD is a syndrome resulting from breakdown of anti-reflux barrier at the lower end of esophagus. This breakdown of anti-reflux barrier results in reflux of gastric contents into the esophagus. Mechanisms for the anti-reflux barrier breakdown are thought to be due to TLESRs and hiatus hernia. Patient with GERD poorly responding to medical treatment should not be precluded from anti-reflux surgery. However, thorough assessment and judicious evaluation is mandatory to confirm the diagnosis of GERD. A substantial proportion of PPI failures show good response to LNF but significantly than clinical response in PPI responders. Increased likelihood of poor outcome after surgery should be discussed with the patient. The aim of this work is to evaluate laparoscopic Nissen fundoplication for patients with gastro esophageal reflux disease non responding to medical treatment. Methods: This study was conducted on 40 patients presented with symptoms of GERD and admitted to Benha University hospital between 2019 and 2021. Results: The results showed that GERD patients who respond well to medication benefit excellently after laparoscopic Nissen procedure, while those who do not respond well to modern medical treatment such as gastric acid secretion inhibitors should not be excluded from anti-reflux surgery, especially if a comprehensive evaluation is done by a method This is necessary to confirm the diagnosis of GERD, and this is clearly shown in the good response to the laparoscopic Nissin operation in these patients compared to patients who continue on medication only without the laparoscopic Nissin operation. But the surgeon must explain to the patient the extent of the long-term benefit from the procedure. Finally, the study proved that the Nissen operation for gastro-oesophageal reflux is a good way to treat patients' weakness or lack of response to medications, and some sources consider it the appropriate treatment for these cases. The results showed that there was no difference between the laparoscopic Nesin operation or the surgical incision, with the necessity of conducting a test to measure the pressure of the lower esophageal muscle to exclude diseases accompanied by symptoms similar to cases of gastroesophageal reflux disease. Finally, the study proved that surgical operations for gastroesophageal reflux disease are a good way to treat these cases, and some sources consider it the only treatment for these cases. Conclusion: Laparoscopic Nissen fundoplication is a safe and effective procedure for gastro-esophageal reflux disease. With experience, the duration of operation falls and the hospital stay is shorter. Short- term symptomatic and $\mathrm{pH}$ results are consistently improved by surgery. It was found that GERD can be treated, with good results, by laparoscopic Nissen fundoplication when medical treatment fails. The procedure can be performed effectively and safely locally.
\end{abstract}

Key words: Laparoscopic Nissen, Fundoplication, Gastro, Esophageal Reflux.

\section{Introduction}

Laparoscopic Nissen fundoplication has become the method of choice in anti-reflux surgery replacing its open counterpart. Laparoscopic fundoplication is nowadays accepted as the routine surgical approach in moderate or severe gastro-esophageal reflux disease [1].

The Nissen Fundoplication was first executed by Dr. Rudolph Nissen in 1955. Nissen called his procedure "gastroplication" but it was later renamed after him in the 1970s after gaining popularity. The surgical procedure was initially performed by an open technique but is now commonly accomplished laparoscopically for a multitude of reasons. Nissen Fundoplication is a complete or total wrap that encompasses 360 o of esophagus in a posterior fashion [2].

The Nissen procedure has been the most successful for controlling gastroesophageal reflux disease (GERD). For example, Patti et al. have found that laparoscopic total fundoplication is more effective than partial fundoplication in curing GERD. Furthermore, esophageal motility measurements may be more appropriate for distinguishing between esophageal motility disorders and gastroesophageal reflux disease. These measurements, however, may not directly indicate which fundoplication is the best [3].

The economic impact of GERD is significant and complicated. To fully understand, one must consider both direct and indirect costs. Direct health care costs 
include those incurred during office visits, diagnostic testing, medical or surgical treatment and hospital admissions. Indirect costs include those from missed work, diminished productivity, and impairment in performing daily activities. The indirect costs due to GERD related impacts have been shown to be profound, yet responsive to effective treatment [4].

There is no high-level evidence to support the use of laparoscopic fundoplication (LF) in partial Responders to proton pump inhibitors (PPI) therapy. The evidence that does exist suggests laparoscopic fundoplication LF improves symptom control in these patients, but symptoms recur over time. There are limited data to suggest that LF is not as effective in partial responders as in those with an adequate response to PPI therapy[5].

GERD symptoms can also be treated surgically by the fundoplication technique, which involves wrapping the gastric fundus partly or completely around the lower end of the esophagus. More recently, the introduction of laparoscopic techniques has reduced perioperative complications and facilitated postoperative recovery, without compromising the level of GERD control. These improvements could increase the likelihood of patients being referred for this procedure [6].

The fundoplication should be placed above the hepatic branch of the anterior vagal nerve and passing the posterior fundic lip through a window between the posterior vagus nerve and the posterior esophageal wall and extending above the gastroesophageal junction Following this recommendation avoids placing the fundoplication too low or too high and reduces the frequency of a slipped fundoplication [7].

The status of the Nissen fundoplication, as assessed by retrograde endoscopy, was significantly associated with the results of the $\mathrm{pH}$ study. A meant cant association was found if any abnormality of the fundoplication was present, but on univariate and multivariate analyses the factor most significantly associated with the $\mathrm{pH}$ study was the presence of an intact, normally located fundoplication compared to a fundoplication that was either disrupted or abnormally located [8].

If surgery can be a valuable option in refractory patients, there is yet no consensus regarding how patient's selection should be obtained, and especially if preoperative ambulatory reflux monitoring should be performed 'off' or 'on' PPIs. Some data suggest that if no esophagitis is present at baseline, a positive 24-hour pH monitoring 'off' PPIs preoperatively (i.e., either abnormal esophageal acid exposure or positive symptom association analysis) is associated with favorable outcome after fundoplication[9].

The management of patients with refractory reflux symptoms is challenging, especially when laparoscopic fundoplication is considered. In these patients, fundoplication has less favorable clinical outcome compared to patients with adequate PPI symptom control [10].
The aim of this work is to evaluate laparoscopic Nissen fundoplication for patients with gastro esophageal reflux disease non responding to medical treatment.

\section{Patients and Methods}

This study was performed on 40 patients suffering from gastro esophageal reflux disease GERD nonresponding to medical treatment presenting to Benha University hospital at period starting from June 2019 to June 2021. Poor responders were those who experienced persistent reflux symptoms, more than once a week, after at least 2 months of maintenance therapy of PPI (20-40 mg daily).

Informed consent was obtained from all patients to be included in this study, after a careful explanation of the nature of the disease and possible treatment with its complications.

Patients in this study divided into two groups as follow:

- Group I: Included 20 patients suffering from gastro esophageal reflux disease GERD responding to medical treatment.

- Group II: included 20 patients suffering from gastro esophageal reflux disease GERD nonresponding to medical treatment.

\section{Inclusion criteria}

All patients had symptomatic GERD; most patients had usually more than one complaint. Heartburn and regurgitation were the main complaints in all cases.

All cases received medical treatment in the form of antacids, H2 Blockers, Proton pump inhibitors and motility promoting drugs for variable durations at least 4 months.

\section{Exclusion criteria}

Patients with history of previous esophageal or gastric surgeries, neurological diseases, complicated GERD by Barrett's esophagus or peptic stricture, collagen diseases, inflammatory bowel disease and those with neoplastic diseases.

\section{They will be subjected to:}

Full History taking.

- Personal data.

- History of Heart burn, epigastric pain with dysphagia and regurgitation.

\section{Examination:}

- General examination.

- Local abdominal examination.

\section{Preoperative assessment}

- Prior to surgery, all patients subjected to a physical examination and asked to complete a written questionnaire in the outpatient office regarding heart burn, regurgitation, epigastric pain and dysphagia

- Barium study in head down position

- Upper gastrointestinal Endoscopy to exclude other disease and to assess any mucosal injury red inflamed mucosa often with ulceration or Sliding 
hernia. Mucosal biopsy to confirm metaplastic transformation.

- Esophageal manometry to assess the motility of LES, Length and pressure of LES.

- 24 hours esophageal $\mathrm{pH}$ monitoring.

- Routine investigations: CBC, SGOT, SGPT, HCV-Ab, HBsAg, FBS, urea, creatinine, bleeding time and coagulation time

Operative Technique

- Laparoscopic Nissen fundoplication.

Preoperative Phase

- After induction of general endotracheal anesthesia, an orogastric tube is inserted to keep the stomach decompressed. The patient is positioned supine in low lithotomy position with the lower extremities extended on stirrups, with knees flexed $20^{\circ}-30^{\circ}$. The surgeon stands between the patient's legs, and the first and second assistants on the left and right sides of the operating table, respectively.

Ports placement and pneumoperitoneum

Pneumoperitoneum by carbon dioxide (CO2) up to $15 \mathrm{mmHg}$ is achieved by inserting a verses needle at the umbilicus. A five-ports (one $10 \mathrm{~mm}$ - and four 5$\mathrm{mm}$ ports) technique is used. At first we place the camera port cautiously in a blind manner; all other ports are placed under direct vision from the camera. Numerous options exist for port placement during a laparoscopic Nissen fundoplication. We used standard five ports for the operation. Port 1 is $10 \mathrm{~mm}$ placed supraumbilical in the midline $15-20 \mathrm{~cm}$ from the xiphoid process. This port is used for insertion of the $30^{\circ}$ scope. Ports 2 and 3 are $5 \mathrm{~mm}$ placed $\sim 2^{\circ} \mathrm{cm}$ below the right and left costal margins (forming an angle of $\sim 120^{\circ}$ between 2 nd and 3rd ports) fig (1a) or slightly modified as surgeon preference fig (1b). Port 4 is $5 \mathrm{~mm}$ placed at the level of port 1 in the right midclavicular line (this is used for the liver retractor) and port 5 is placed at the level of port 1 in the left midclavicular line Fig. (1b)

Initially explore and assess the hiatus and esophagogastric junction, then the left segment of the liver is retracted by atraumatic retractor, the gastrohepatic ligament is divided starting by opening the pars flaccida fig. (2) toward the right crus saving the qudate lobe of the liver and the inferior vena cava IVC, the right crus is then separated from the right side of the esophagus by blunt dissection and the posterior vagus nerve is identified and preserved.

A-traumatic elevation of the esophagus is done by the left hand, and blunt dissection should be used to separate the right crus from the esophagus by the right hand with no grasping of the esophagus, The right crus should be dissected all the way down toward the junction with the left crus, Fig. (3).

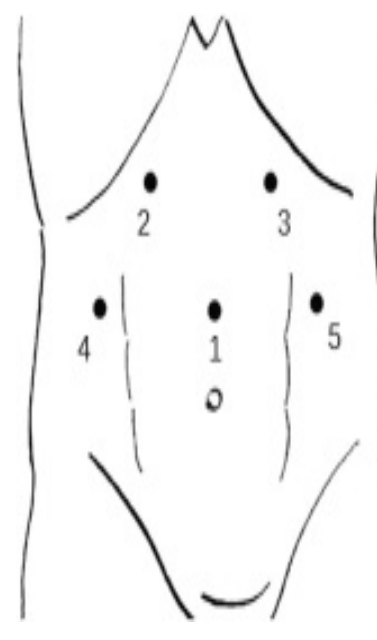

A

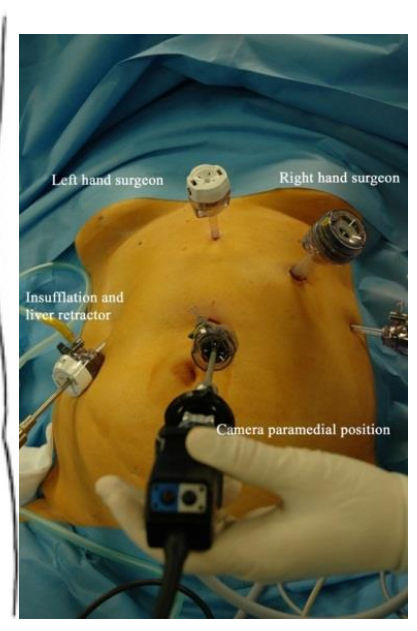

b

Fig. (1) Placement of abdominal por

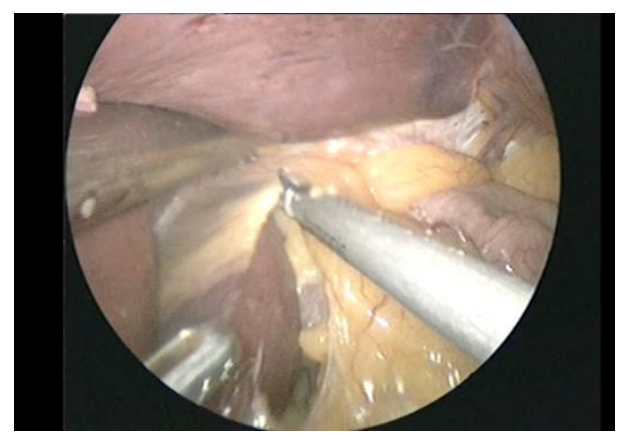

Fig. (2) Division of pars flacida 
Dissection was stopped when the esophagus was separated from both crura, the dissection can be continued superiorly over the anterior surface of the esophagus and down the left crus with the division of the phrenoesophageal ligament fig. (4).

The anterior vagus nerve should be identified and kept attached to the esophagus. A length of about $\sim 5$ $\mathrm{cm}$ of intra-abdominal esophagus is obtained. Blunt dissection can be used to free the distal esophagus from its posterior attachments and the left pillar of the crus is completely separated from the esophagus and dissected bluntly downward toward the junction with the right crus fig. (5).

Achieving Esophageal mobilization and mediastinal dissection
The esophagus is retracted upward at the level of the gastroesophageal junction, and a window under the esophagus is opened by blunt dissection. A tape of gauze is then passed around the esophagus, incorporating both anterior and posterior vagus nerves. The tape should be loosly tied to be used to provide adequate and safe traction on the esophagus. The dissection should be carried up into the mediastinum until at least 3 to $6 \mathrm{~cm}$ of esophagus comes into the abdomen without tension.

We may divide short gastric vessles to get floppy and tension free fundic wrap.

Then hiatal repair and crural closure using non absorbable sutures (2-0 silk or polyester) starting from posterior by two stitches and may completed anteriorly by additional stitch in an intracorporeal manner Fig. (6).

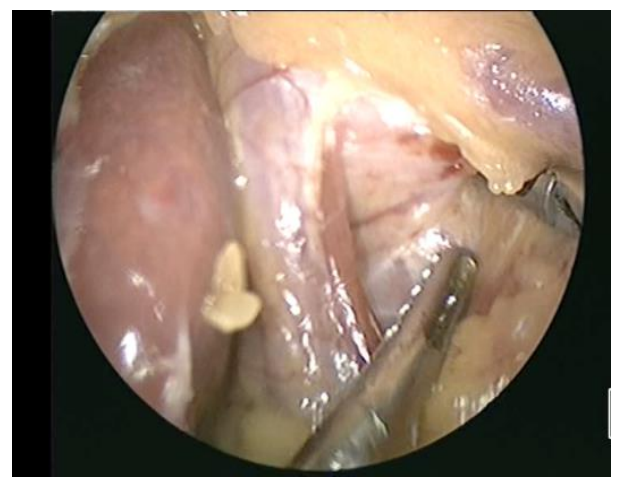

Fig. (3) Dissection of rt crus

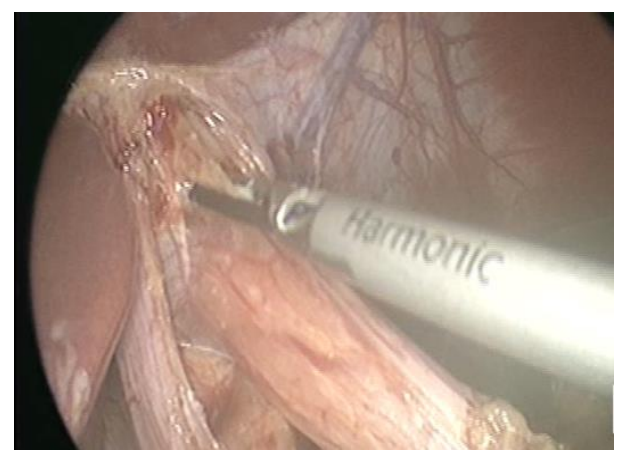

Fig. (4) Division of phrenoesophageal ligament

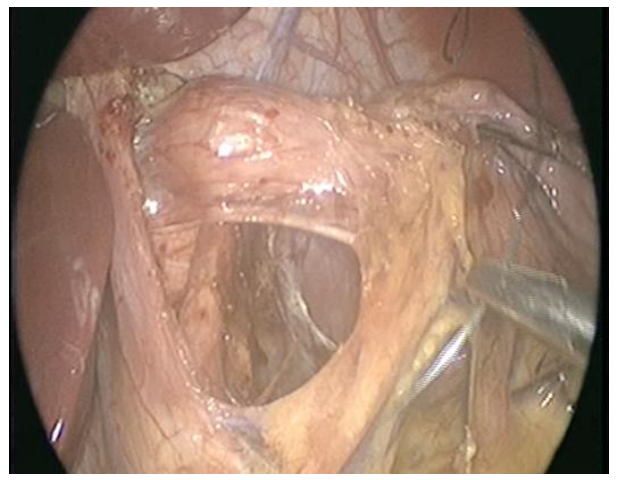

Fig. (5) Complete separation of rt and lt crus keeping posterior vagus intact 


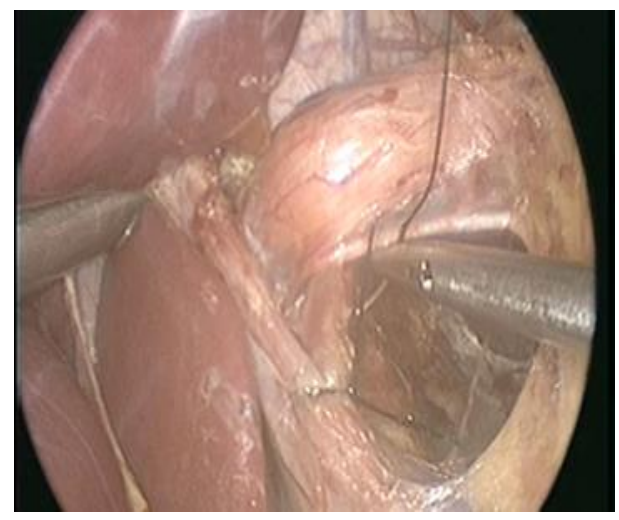

Fig. (6) Crural repair
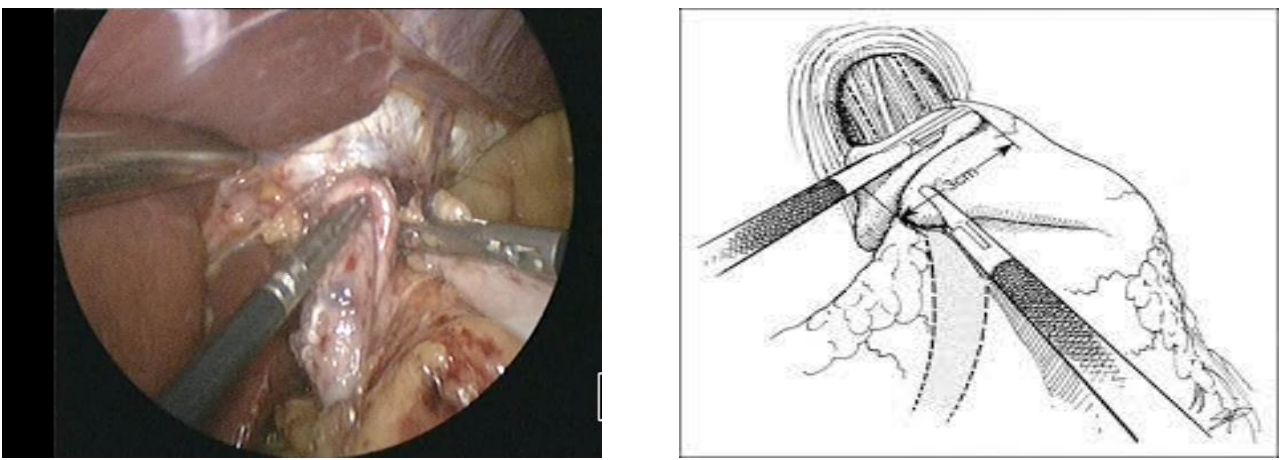

Fig. (7) Passing the floppy fundic wrap freely behind the esophagus (shoe shine mameuver)

The crura should not be too tight, and a closed grasper should slide easily between the esophagus and the crura. In order to complete Nissen fundoplication the anesthesiologist removes the orogastric tube and inserting a 56 to $60 \mathrm{~F}$ lubricated bougie down the esophagus through the esophagogastric junction, advancing it slowly to avoid esophageal perforation. The stomach is passed behind the esophagus and a "shoe-shine" maneuver is performed to verify sufficient fundic mobilization fig. (7).

A $2-4 \mathrm{~cm}$ floppy $360^{\circ}$ fundic wrap was then constructed around the lower esophagus using three interrupted full-thickness non-absorbable sutures (2-0 silk or polyester) including the esophageal wall in the upper suture and the left and right sides of the fundus are wrapped above the esophagogastric junction fig. (8). The goal is to create a short (2-4 to $\mathrm{cm}$ in length) and floppy wrap.

The procedure is finished by removing the bougie, the tape, final inspection of fundoplication, hiatal narrowing and assuring hemostasis.

The ports are removed under direct vision and the pneumo- peritoneum is deflated. The fascia perforated by the $10-\mathrm{mm}$ port is closed using interrupted sutures, the skin is then closed. Dressings are applied.

\section{Postoperative Assessment}

All patients were asked to come for follow-up after 1 week postoperatively, 3 months, 6 months, and then after 1 year. Patients were also seen at outpatient clinics if they developed symptoms between their follow-up visits regarding Allen scoring system.
Twelve distinct GI symptoms were graded individually by the patient as none, mild, moderate, or severe, and converted to a numeric score from 0 (none) to 3 (severe).

Preoperative, postoperative, and long-term surveys all used the same scoring system. The 3 typical symptoms were defined as heartburn, regurgitation, and difficulty swallowing. Atypical symptoms investigated were chest pain, cough, hoarseness, sore throat, throat clearing, and asthma.

Assessment was done including clinical evaluation, endoscopic examination, barium meal study.

Moreover, all patients were asked about their degree of satisfaction from surgery with the highest degree of satisfaction described as excellent when the patient experienced complete recovery, good when he reported major improvement with minor complaints, fair when there were significant complaints and poor when there was no or minor improvement.

\section{Ethical considerations}

- An informed written consent will be obtained from all participants in this research after explanation of the benefits and possible risks of the study and how we will overcome these risks.

- The study carries no risks to the participants as the investigations are noninvasive except for the risk of infection during blood sampling that will be avoided by complete aseptic technique.

- There will be safe disposal of waste materials e.g. needles, syringes ...etc. 
- There will be a code number for each patient's file that includes all investigations, so all data of the patients will be strictly confidential and the privacy will be granted.

- Any unexpected risks appeared during the course of the research will be cleared to participants and the research ethical committee on time.

Statistical Analysis

Statistical presentation and analysis of the present study was conducted, using the mean, standard deviation and chi-square test by SPSS V.22.

\section{Results}

The age of patients in this study ranged between 18 and 50 years with a mean age of 31 years. It was found that patients above 40 years were 10 and those below 40 years were 30 patients.

According to age there is no-significant difference between responding with rang (19-49 years) (32.35 \pm 9.98) and non-responding with rang (18 - 50 years) $(29.60 \pm 9.90)$ to PPIs cases.

Table (1) Comparison between responding and none responding to PPIs cases according to age

\begin{tabular}{lll}
\hline Age & Responding & Not responding \\
\hline Range & $19-49$ & $18-50$ \\
Mean \pm SD & $32.35 \pm 9.98$ & $29.60 \pm 9.90$ \\
T. test & 0.875 & \\
P. value & 0.387 & \\
\hline
\end{tabular}

Increased body mass index (BMI) and obesity, are strongly associated with GERD symptoms. We have16 cases BMI ranges from 25 to 30 with no significant difference between responding and non-responding to PPIs cases according to BMI.

Table (2) Comparison between responding and non-responding to PPIs cases according to BMI

\begin{tabular}{lll}
\hline BMI & Responding & Not responding \\
\hline Range & $21.3-28.1$ & $21.5-27.4$ \\
Mean \pm SD & $24.51 \pm 1.92$ & $24.74 \pm 1.62$ \\
T. test & 0.401 & \\
P. value & 0.691 & \\
\hline
\end{tabular}

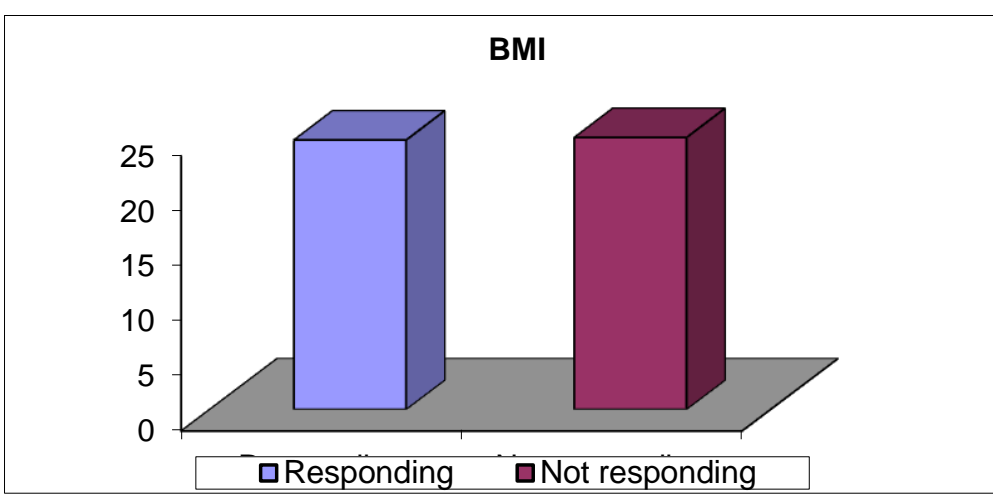

Fig. (2) Comparison between responding and non-responding to PPIs cases according to BMI

The duration of medical treatment was at least 4 months up to 13 months in both groups. non responding group (20 patients) were those who experienced persistent reflux symptoms, more than once a week, after at least 2 months of maintenance therapy of PPI (20-40 mg daily).

Table (3) Comparison between responding and non-responding to PPIs cases according to duration of medical treatment

\begin{tabular}{|c|c|c|}
\hline Duration & Responding & Not responding \\
\hline Range & $4-13$ & $4-12$ \\
\hline Mean \pm SD & $8.25 \pm 2.79$ & $7.80 \pm 2.26$ \\
\hline T. test & & \\
\hline P. value & & \\
\hline
\end{tabular}

All patients underwent preoperative functional assessment by esophageal manometric study to assess the pressure of LES in both groups. The pre-operative mean LESP in responding was $(12.72 \pm 4.03)$ while in non-responding was $(10.41 \pm 4.79)$ with significant difference between responding and non-responding cases according to LESP. 
Table (4) Comparison between responding and non-responding to PPIs cases according to LESP

\begin{tabular}{|c|c|c|}
\hline LESP & Responding & Not responding \\
\hline Range & $6.5-20.5$ & $5.8-20.3$ \\
\hline Mean \pm SD & $12.72 \pm 4.03$ & $10.41 \pm 4.79$ \\
\hline T. test & & \\
\hline P. value & & \\
\hline
\end{tabular}

Regarding preoperative LESR study there is no significant difference in both GERD groups as the mean LESR was $98.25 \pm 2.75$ in PPI responders and $98.49 \pm 2.33$ in PPI non responders.

Table (5) Comparison between responding and non-responding to PPIs cases according to LESR

\begin{tabular}{lccc}
\hline LESR & Responding & Not responding \\
\hline Range & $91-102.3$ & & $95.8-102.8$ \\
Mean \pm SD & $98.25 \pm 2.75$ & & $98.49 \pm 2.33$ \\
T. test & & 0.298 & \\
P. value & & 0.767 & \\
\hline
\end{tabular}

It was shown that the number of patients as regard the sex was 15 males and 25 females. Although it is increased in females but no significant difference Gerd incidence in both sexes.

Table (6) Comparison between responding and non-responding to PPIs cases according to sex

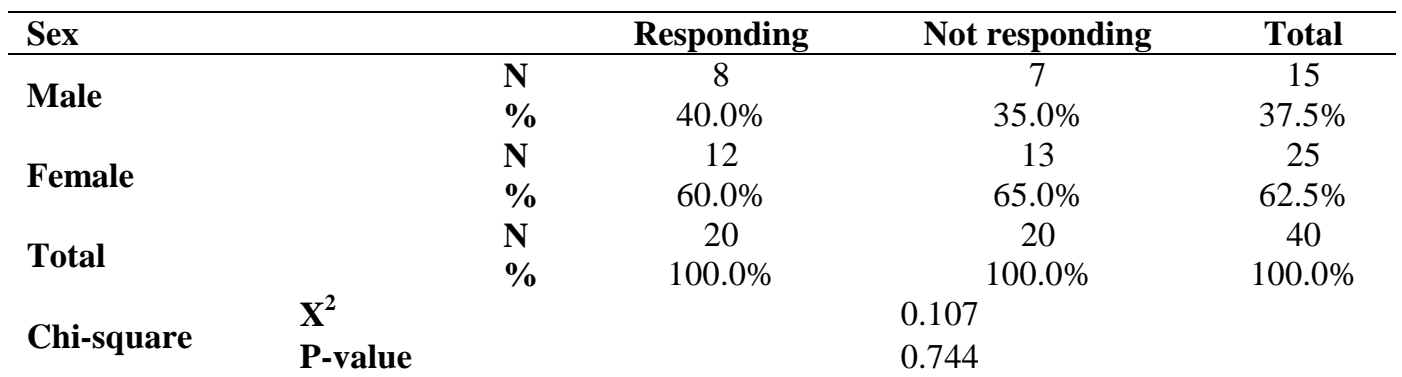

In this study we found 17 smoker patients, 8 of them were responding to PPIs medications and 9 were not responding. smoking increase severity of symptoms rather than resistance to medication.

Table (7) Comparison between responding and non-responding to PPIs cases according to smoking

\begin{tabular}{|c|c|c|c|c|c|}
\hline Smoking & & & Responding & Not responding & Total \\
\hline \multirow{2}{*}{ Yes } & & $\mathbf{N}$ & 8 & 9 & 17 \\
\hline & & $\%$ & $40.0 \%$ & $45.0 \%$ & $42.5 \%$ \\
\hline \multirow{2}{*}{ No } & & $\mathbf{N}$ & 12 & 11 & 23 \\
\hline & & $\%$ & $60.0 \%$ & $55.0 \%$ & $57.5 \%$ \\
\hline \multirow{2}{*}{ Total } & & $\mathbf{N}$ & 20 & 20 & 40 \\
\hline & & $\%$ & $100.0 \%$ & $100.0 \%$ & $100.0 \%$ \\
\hline \multirow{2}{*}{ Chi-square } & $\mathbf{X}^{2}$ & 0.102 & & & \\
\hline & P-value & 0.749 & & & \\
\hline
\end{tabular}

In this study most of the patients presented with more than one symptom, most of them (37) patients with Heart burn as the main complaint in a variable degree from mild to severe in both comparative groups. Finding no significant difference in responding (18) and non-responding (19) cases to medications.

Table (8) Comparison between responding and non-responding to PPIs cases according to Heart bur

\begin{tabular}{lcccc}
\hline Heart burn & & Responding & Not responding & Total \\
\hline No & $\mathbf{N}$ & 2 & 1 & 3 \\
& $\boldsymbol{\%}$ & $10.0 \%$ & $5.0 \%$ & $7.5 \%$ \\
Mild & $\mathbf{N}$ & 2 & 3 & 5 \\
& $\boldsymbol{\%}$ & $10.0 \%$ & $15.0 \%$ & $12.5 \%$ \\
Moderate & $\mathbf{N}$ & 6 & 7 & 13 \\
Severe & $\boldsymbol{\%}$ & $30.0 \%$ & $35.0 \%$ & $32.5 \%$ \\
\hline
\end{tabular}




\begin{tabular}{lllccc}
\hline \multirow{4}{*}{ Total } & & $\mathbf{\%}$ & $50.0 \%$ & $45.0 \%$ & $47.5 \%$ \\
& & $\mathbf{N}$ & 20 & 20 & 40 \\
\multirow{2}{*}{ Chi-square } & $\mathbf{\%}$ & $100.0 \%$ & $100.0 \%$ & $100.0 \%$ \\
& $\mathbf{X}^{\mathbf{2}}$ & 0.663 & & & \\
\hline
\end{tabular}

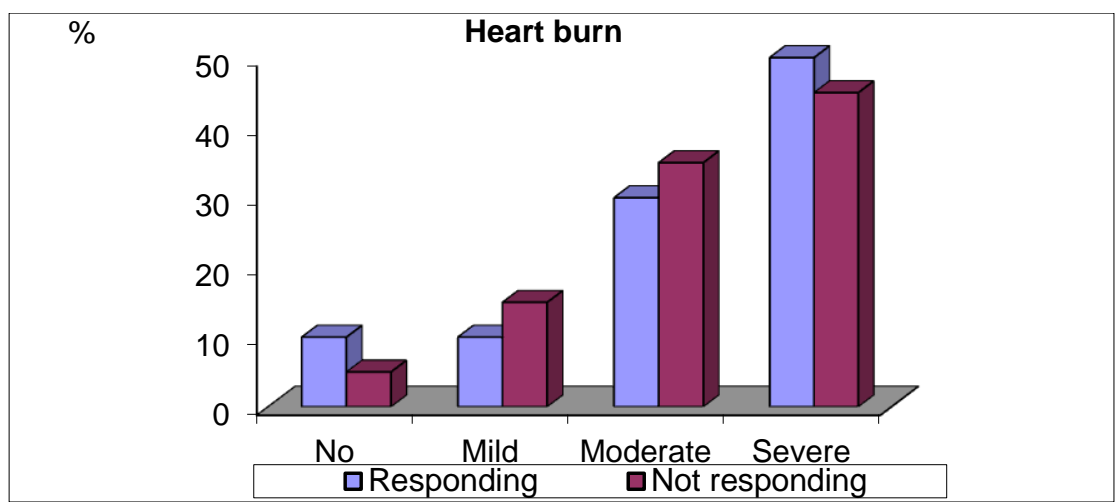

Fig. (8) Comparison between responding and non-responding to PPIs cases according to Heart burn.

Most of the patients (35) in both comparative groups presented with regurgitation symptom with variable degree from mild to severe, (18) of them belongs non responding group. With no significant difference in both groups regarding regurgitation.

Table (9) Comparison between responding and non-responding to PPIs cases according to Regurgitation

\begin{tabular}{|c|c|c|c|c|c|}
\hline \multicolumn{3}{|l|}{ Regurgitation } & Responding & Not responding & Total \\
\hline \multirow{2}{*}{ No } & & $\mathbf{N}$ & 3 & 2 & 5 \\
\hline & & $\%$ & $15.0 \%$ & $10.0 \%$ & $12.5 \%$ \\
\hline \multirow{2}{*}{ Mild } & & $\mathbf{N}$ & 8 & 7 & 15 \\
\hline & & $\%$ & $40.0 \%$ & $35.0 \%$ & $37.5 \%$ \\
\hline \multirow{2}{*}{ Moderate } & & $\mathbf{N}$ & 6 & 7 & 13 \\
\hline & & $\%$ & $30.0 \%$ & $35.0 \%$ & $32.5 \%$ \\
\hline \multirow{2}{*}{ Severe } & & $\mathbf{N}$ & 3 & 4 & 7 \\
\hline & & $\%$ & $15.0 \%$ & $20.0 \%$ & $17.5 \%$ \\
\hline \multirow{2}{*}{ Total } & & $\mathbf{N}$ & 20 & 20 & 40 \\
\hline & & $\%$ & $100.0 \%$ & $100.0 \%$ & $100.0 \%$ \\
\hline \multirow{2}{*}{ Chi-square } & $\mathrm{X}^{2}$ & 0.486 & & & \\
\hline & P-value & 0.922 & & & \\
\hline
\end{tabular}

In our study there are12 patients suffering from dysphagia (painful swallowing) equal in number in both comparative groups but all cases in responding group presented by mild degree. Non-significant difference between responding and non-responding to PPIs cases according to Dysphagia.

Table (10) Comparison between responding and non-responding to PPIs cases according to Dysphagia

\begin{tabular}{|c|c|c|c|c|c|}
\hline \multicolumn{3}{|l|}{ Dysphagia } & Responding & Not responding & Total \\
\hline \multirow{2}{*}{ No } & & $\mathbf{N}$ & 14 & 14 & 28 \\
\hline & & $\%$ & $70.0 \%$ & $70.0 \%$ & $70.0 \%$ \\
\hline \multirow{2}{*}{ Mild } & & $\mathbf{N}$ & 6 & 5 & 11 \\
\hline & & $\%$ & $30.0 \%$ & $25.0 \%$ & $27.5 \%$ \\
\hline \multirow{2}{*}{ Moderate } & & $\mathbf{N}$ & 0 & 1 & 1 \\
\hline & & $\%$ & $.0 \%$ & $5.0 \%$ & $2.5 \%$ \\
\hline \multirow{2}{*}{ Total } & & $\mathbf{N}$ & 20 & 20 & 40 \\
\hline & & $\%$ & $100.0 \%$ & $100.0 \%$ & $100.0 \%$ \\
\hline \multirow{2}{*}{ Chi-square } & $\mathbf{X}^{2}$ & 1.091 & & & \\
\hline & P-value & 0.580 & & & \\
\hline
\end{tabular}

Patients presented with atypical symptoms (asthma, chest pain and cough). In both comparative groups were (14). Most of them (11) were in non-responding group mainly cough symptom (7). Significant difference between patients suffering atypical symptoms as responding group was (15\%) and non-responding group was (55\%). 
Table (11) Comparison between responding and non-responding to PPIs cases according to atypical symptoms

\begin{tabular}{|c|c|c|c|c|}
\hline \multicolumn{2}{|l|}{ Atypical symptoms } & Responding & Not responding & Total \\
\hline & $\mathbf{N}$ & 17 & 9 & 26 \\
\hline No & $\%$ & $85.0 \%$ & $45.0 \%$ & $65.0 \%$ \\
\hline & $\mathbf{N}$ & 1 & 3 & 4 \\
\hline Asthma & $\%$ & $5.0 \%$ & $15.0 \%$ & $10.0 \%$ \\
\hline & $\mathbf{N}$ & 1 & 1 & 2 \\
\hline Chest pain & $\%$ & $5.0 \%$ & $5.0 \%$ & $5.0 \%$ \\
\hline Cough & $\mathbf{N}$ & 1 & 7 & 8 \\
\hline Cougin & $\%$ & $5.0 \%$ & $35.0 \%$ & $20.0 \%$ \\
\hline Total & $\mathbf{N}$ & 20 & 20 & 40 \\
\hline 10tal & $\%$ & $100.0 \%$ & $100.0 \%$ & $100.0 \%$ \\
\hline $\begin{array}{l}X^{2} \\
P \text {-value }\end{array}$ & $\begin{array}{l}7.962 \\
0.047 *\end{array}$ & & & \\
\hline
\end{tabular}

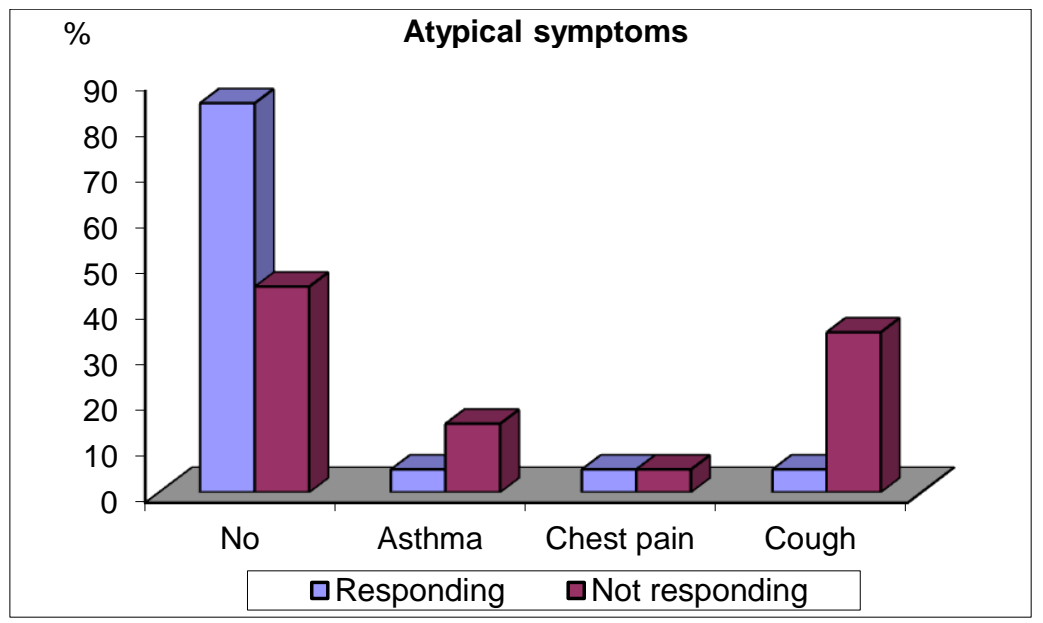

Fig. (11) Comparison between responding and non-responding to PPIs cases according to atypical symptoms. All patients (40) underwent Esophagogastroduodenoscopy to assess the degree of esophagitis regarding savary miller classification fig (10) concluding only 4 patients (10\%) were NERD, $36(90 \%)$ have variable degree of esophagitis. Barrett's esophagus was excluded. With no significant difference in endoscopic esophagitis but more severe in responding group.

Table (12) Comparison between responding and non-responding groups according to Endoscopic esophagitis

\begin{tabular}{|c|c|c|c|c|}
\hline \multicolumn{2}{|l|}{ Endoscopic esophagitis } & Responding & Not responding & Total \\
\hline \multirow[t]{2}{*}{$\begin{array}{llll}2 & 1 & 0\end{array}$} & $\mathbf{N}$ & 2 & 2 & 4 \\
\hline & $\%$ & $10.0 \%$ & $10.0 \%$ & $10.0 \%$ \\
\hline \multirow{2}{*}{ I } & $\mathbf{N}$ & 10 & 13 & 23 \\
\hline & $\%$ & $50.0 \%$ & $65.0 \%$ & $57.5 \%$ \\
\hline \multirow{2}{*}{ II } & $\mathbf{N}$ & 5 & 3 & 8 \\
\hline & $\%$ & $25.0 \%$ & $15.0 \%$ & $20.0 \%$ \\
\hline \multirow{2}{*}{ III } & $\mathbf{N}$ & 3 & 2 & 5 \\
\hline & $\%$ & $15.0 \%$ & $10.0 \%$ & $12.5 \%$ \\
\hline \multirow{2}{*}{ Total } & $\mathbf{N}$ & 20 & 20 & 40 \\
\hline & $\%$ & $100.0 \%$ & $100.0 \%$ & $100.0 \%$ \\
\hline \multirow{2}{*}{ Chi-square } & 1.091 & & & \\
\hline & 0.779 & & & \\
\hline
\end{tabular}

Non-significant difference between responding and non-responding to PPIs cases according to Endoscopic esophagitis. All patient under went to barium esophagogram to assess anatomical and radiological reflux shown in variable degrees mostly corresponding to mild degree in both groups 62.5 (25 patients). 
Table (13) Comparison between responding and non-responding to PPIs cases according to Radiological reflux

\begin{tabular}{|c|c|c|c|c|}
\hline Radiological reflux & & Responding & Not responding & Total \\
\hline \multirow{2}{*}{ No } & $\mathbf{N}$ & 3 & 2 & 5 \\
\hline & $\%$ & $15.0 \%$ & $10.0 \%$ & $12.5 \%$ \\
\hline \multirow{2}{*}{ Mild } & $\mathbf{N}$ & 13 & 12 & 25 \\
\hline & $\%$ & $65.0 \%$ & $60.0 \%$ & $62.5 \%$ \\
\hline \multirow{2}{*}{ Moderate or Severe } & $\mathbf{N}$ & 4 & 6 & 10 \\
\hline & $\%$ & $20.0 \%$ & $30.0 \%$ & $25.0 \%$ \\
\hline \multirow{2}{*}{ Total } & $\mathbf{N}$ & 20 & 20 & 40 \\
\hline & $\%$ & $100.0 \%$ & $100.0 \%$ & $100.0 \%$ \\
\hline Chi-square & $\begin{array}{l}\mathbf{0 . 6 4 0} \\
0.726\end{array}$ & & & \\
\hline
\end{tabular}

Non-significant difference between responding and non-responding to PPIs cases according to Radiological reflux.

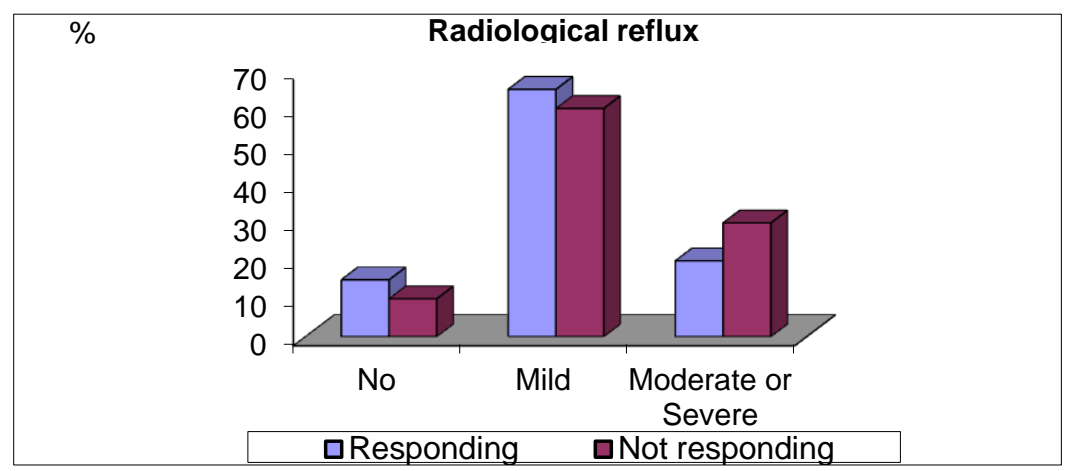

Fig. (13) Comparison between responding and non-responding to PPIs cases according to Radiological reflux Post LNF, all patients evaluated clinically for improvement of heart burn symptom resulting in $70 \%$ (28patient) complete relief, most of them belongs responding group but 30\% (12patient) show partial improvement from mild to severe.

Table (14) Comparison between responding and non-responding to PPIs cases according to Heart burn post

\begin{tabular}{|c|c|c|c|c|c|}
\hline \multicolumn{3}{|c|}{ Heart burn post } & Responding & Not responding & Total \\
\hline \multirow{2}{*}{\multicolumn{2}{|c|}{ No }} & $\mathbf{N}$ & 18 & 10 & 28 \\
\hline & & $\%$ & $90.0 \%$ & $50.0 \%$ & $70.0 \%$ \\
\hline \multirow{2}{*}{\multicolumn{2}{|c|}{ Mild }} & $\mathbf{N}$ & 1 & 1 & 2 \\
\hline & & $\%$ & $5.0 \%$ & $5.0 \%$ & $5.0 \%$ \\
\hline \multirow{2}{*}{\multicolumn{2}{|c|}{ Moderate }} & $\mathbf{N}$ & 1 & 5 & 6 \\
\hline & & $\%$ & $5.0 \%$ & $25.0 \%$ & $15.0 \%$ \\
\hline \multirow{2}{*}{\multicolumn{2}{|c|}{ Severe }} & $\mathbf{N}$ & 0 & 4 & 4 \\
\hline & & $\%$ & $.0 \%$ & $20.0 \%$ & $10.0 \%$ \\
\hline \multirow{2}{*}{\multicolumn{2}{|c|}{ Total }} & $\mathbf{N}$ & 20 & 20 & 40 \\
\hline & & $\%$ & $100.0 \%$ & $100.0 \%$ & $100.0 \%$ \\
\hline Chi-square & $\begin{array}{l}X^{2} \\
P \text {-value }\end{array}$ & $\begin{array}{l}8.952 \\
0.030 *\end{array}$ & & & \\
\hline
\end{tabular}

Significant difference in responding (2 patient $5 \%$ ) in comparison to (10 patients $25 \%$ ) in non-responding group cases according to Heart burn post LNF.

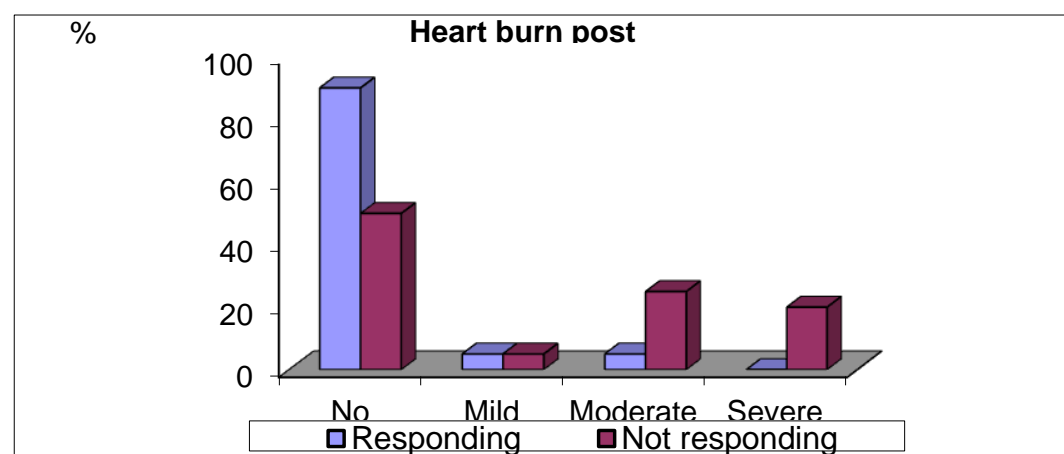

Fig. (13) Comparison between responding and non-responding to PPIs cases according to Heart burn post All patients evaluated clinically post LNF for still having regurgitation, founding there is $82.5 \%$ (33) completely improved with no regurgitation but 17.5 (7) still had mild degree of regurgitation most of them $15 \%$ (6). 
Table (15) Comparison between responding and non-responding to PPIs cases according to Regurgitation post

\begin{tabular}{|c|c|c|c|c|c|}
\hline \multicolumn{2}{|c|}{ Regurgitation post } & & Responding & Not responding & Total \\
\hline \multirow{2}{*}{\multicolumn{2}{|c|}{ No }} & $\mathbf{N}$ & 19 & 14 & 33 \\
\hline & & $\%$ & $95.0 \%$ & $70.0 \%$ & $82.5 \%$ \\
\hline \multirow{2}{*}{\multicolumn{2}{|c|}{ Mild }} & $\mathbf{N}$ & 1 & 6 & 7 \\
\hline & & $\%$ & $5.0 \%$ & $30.0 \%$ & $17.5 \%$ \\
\hline \multirow{2}{*}{\multicolumn{2}{|c|}{ Total }} & $\mathbf{N}$ & 20 & 20 & 40 \\
\hline & & $\%$ & $100.0 \%$ & $100.0 \%$ & $100.0 \%$ \\
\hline Chi-square & $\begin{array}{l}X^{2} \\
P \text {-value }\end{array}$ & $\begin{array}{l}4.329 \\
0.037 *\end{array}$ & & & \\
\hline
\end{tabular}

Significant improvement in responding group (1 patient $2.5 \%)$ to (6 patients $15 \%)$ in non-responding group regarding regurgitation in both groups post LNF.

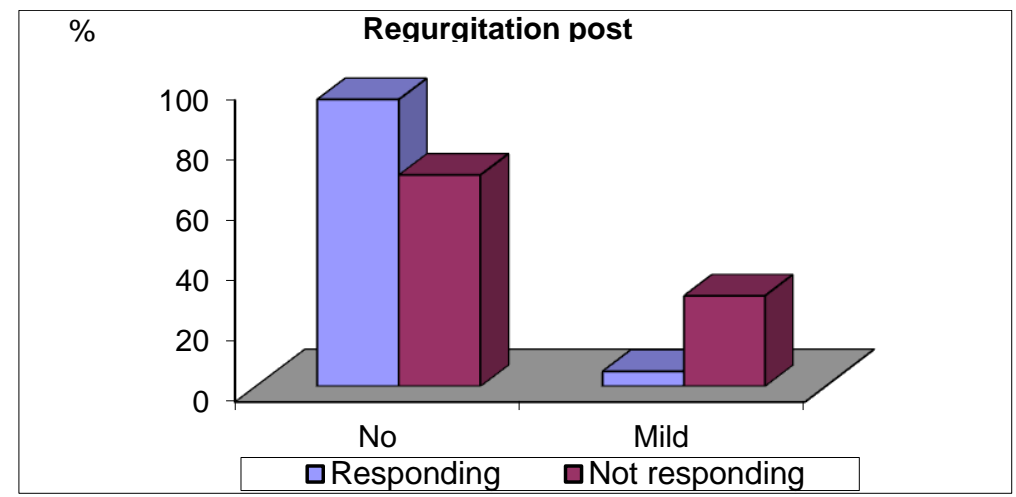

Fig. (15) Comparison between responding and non-responding to PPIs cases according to Regurgitation post Clinically we found 5 patients (12.5\%) still suffering from dysphagia 3 of them in non-responding group (7.5).

Table (9) Comparison between responding and non-responding groups according to Dysphagia post LNF

\begin{tabular}{|c|c|c|c|c|c|}
\hline \multicolumn{3}{|c|}{ Dysphagia post } & Responding & Not responding & Total \\
\hline \multirow{2}{*}{\multicolumn{2}{|c|}{ No }} & $\mathbf{N}$ & 18 & 17 & 35 \\
\hline & & $\%$ & $90.0 \%$ & $85.0 \%$ & $87.5 \%$ \\
\hline \multirow{2}{*}{\multicolumn{2}{|c|}{ Mild }} & $\mathbf{N}$ & 2 & 2 & 4 \\
\hline & & $\%$ & $10.0 \%$ & $10.0 \%$ & $10.0 \%$ \\
\hline \multicolumn{2}{|l|}{ Moderate } & $\begin{array}{l}\mathbf{N} \\
\%\end{array}$ & $\begin{array}{c}0 \\
0 \%\end{array}$ & $\begin{array}{c}1 \\
50 \%\end{array}$ & $25 \%$ \\
\hline \multicolumn{2}{|l|}{ Total } & $\mathbf{O}$ & $\begin{array}{c}20 \\
1000 \%\end{array}$ & $\begin{array}{l}20 \\
1000 \%\end{array}$ & $\begin{array}{c}40 \\
100.0 \%\end{array}$ \\
\hline Chi-square & $\begin{array}{l}\mathrm{X}^{2} \\
\mathrm{P} \text {-value }\end{array}$ & $\begin{array}{l}1.029 \\
0.598 \\
\end{array}$ & & & \\
\hline
\end{tabular}

Non-significant difference between responding and non-responding groups c according to Dysphagia post LNF.

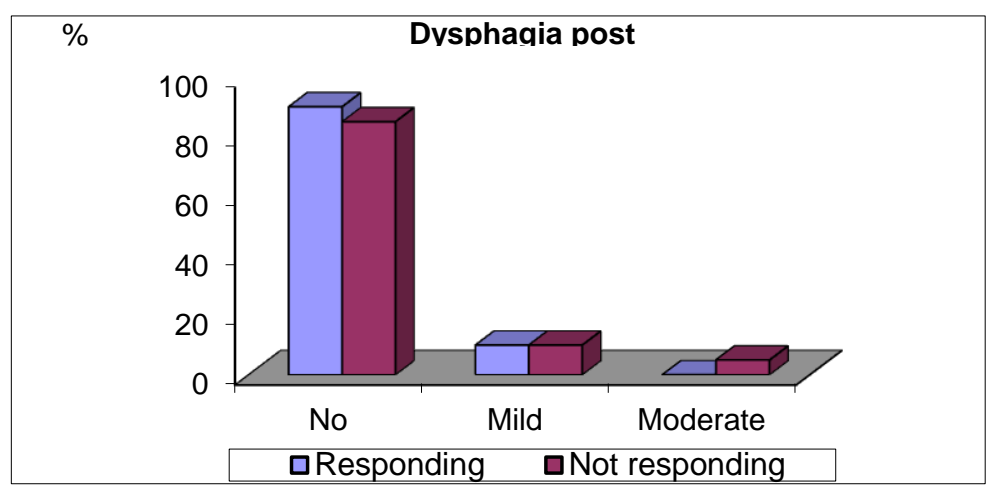

Fig. (15) Comparison between responding and non-responding to PPIs cases according to Dysphagia post Regarding persistent atypical reflux symptoms post LNF we found 5 patients $12.5 \%$ still had atypical symptom mainly cough symptom 4 of them(10\%) corresponding to non-responding group. 
Table (17) Comparison between responding and non-responding to PPIs cases according to atypical symptoms post

\begin{tabular}{|c|c|c|c|c|}
\hline Atypical symptoms post & & Responding & Not responding & Total \\
\hline \multirow{2}{*}{ No } & $\mathbf{N}$ & 19 & 16 & 35 \\
\hline & $\%$ & $95.0 \%$ & $80.0 \%$ & $87.5 \%$ \\
\hline \multirow{2}{*}{ Asthma } & $\mathbf{N}$ & 0 & 1 & 1 \\
\hline & $\%$ & $.0 \%$ & $5.0 \%$ & $2.5 \%$ \\
\hline \multirow{2}{*}{ Chest pain } & $\mathbf{N}$ & 0 & 0 & 0 \\
\hline & $\%$ & $.0 \%$ & $.0 \%$ & $.0 \%$ \\
\hline \multirow{2}{*}{ Cough } & $\mathbf{N}$ & 1 & 3 & 4 \\
\hline & $\%$ & $5.0 \%$ & $15.0 \%$ & $10.0 \%$ \\
\hline \multirow{2}{*}{ Total } & $\mathbf{N}$ & 20 & 20 & 40 \\
\hline & $\%$ & $100.0 \%$ & $100.0 \%$ & $100.0 \%$ \\
\hline \multirow{2}{*}{ Chi-square } & 2.257 & & & \\
\hline & 0.323 & & & \\
\hline
\end{tabular}

Non-significant difference between responding and non-responding groups post LNF according to Atypical symptoms.

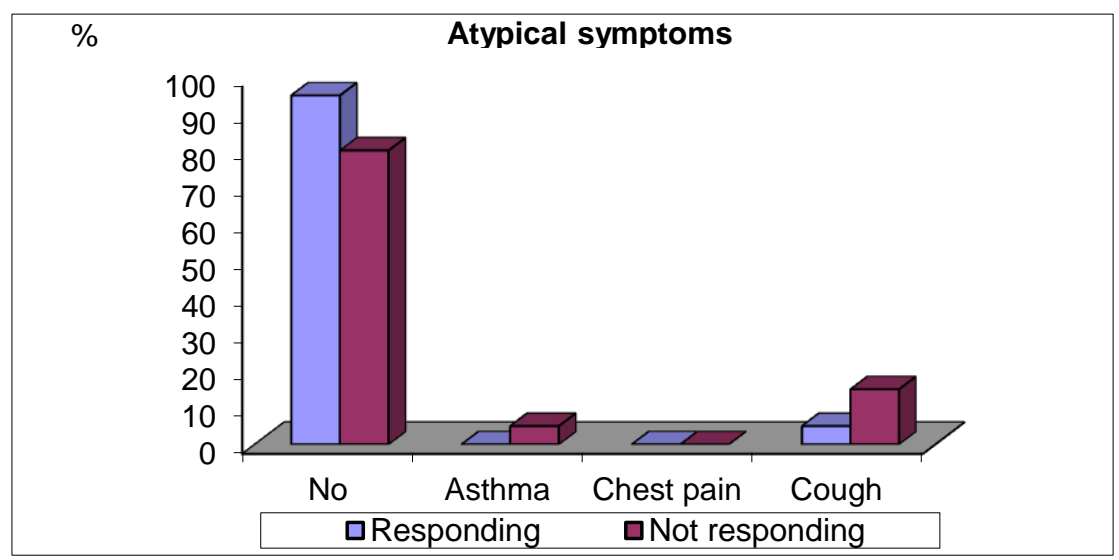

Fig. (17) Comparison between responding and non-responding post LNF according to atypical symptoms. Post LNF (32) patients adopted for upper Gi endoscopy, (2) of them showed esophagitis in responding group with variable degrees and (5) of them in non-responding group in variable degrees regarding (savary miller) classification.

Table (18) Comparison between responding and non-responding to PPIs cases according to Endoscopic esophagitis post

\begin{tabular}{|c|c|c|c|c|c|}
\hline \multicolumn{3}{|c|}{ Endoscopic esophagitis post } & \multirow{2}{*}{$\begin{array}{c}\text { Responding } \\
13\end{array}$} & \multirow{2}{*}{$\begin{array}{c}\text { Not responding } \\
12\end{array}$} & \multirow{2}{*}{$\begin{array}{c}\text { Total } \\
25\end{array}$} \\
\hline 0 & & $\mathbf{N}$ & & & \\
\hline 0 & & $\%$ & $86.7 \%$ & $70.6 \%$ & $78.1 \%$ \\
\hline & & $\mathbf{N}$ & 1 & 3 & 4 \\
\hline I & & $\%$ & $6.7 \%$ & $17.6 \%$ & $12.5 \%$ \\
\hline U & & $\mathbf{N}$ & 1 & 2 & 3 \\
\hline 11 & & $\%$ & $6.7 \%$ & $11.8 \%$ & $9.4 \%$ \\
\hline Totol & & $\mathbf{N}$ & 15 & 17 & 32 \\
\hline Iotal & & $\%$ & $100.0 \%$ & $100.0 \%$ & $100.0 \%$ \\
\hline Chi-square & $\begin{array}{l}X^{2} \\
\text { P-value }\end{array}$ & $\begin{array}{l}1.253 \\
0.534\end{array}$ & & & \\
\hline
\end{tabular}

Non-significant difference between responding and non-responding groups post LNF according to Endoscopic esophagitis. 


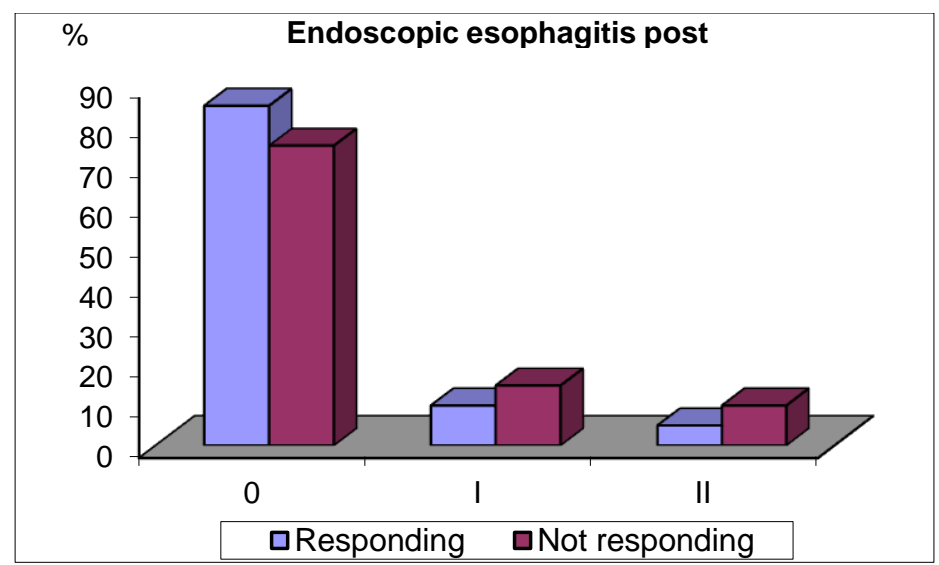

Fig. (18) Comparison between responding and non-responding to PPIs cases according to Endoscopic esophagitis post According to (barium esophagography) post LNF there were 2 patients in responding group had radiological reflux and 4 patients in non-responding group had.

Table (19) Comparison between responding and non-responding groups post LNF according to Radiological reflux.

\begin{tabular}{|c|c|c|c|c|}
\hline Radiological reflux post & & Responding & Not responding & Total \\
\hline \multirow{2}{*}{ No } & $\mathbf{N}$ & 13 & 14 & 27 \\
\hline & $\%$ & $86.7 \%$ & $82.4 \%$ & $84.4 \%$ \\
\hline \multirow{2}{*}{ Mild } & $\mathbf{N}$ & 1 & 3 & 4 \\
\hline & $\%$ & $6.7 \%$ & $17.6 \%$ & $12.5 \%$ \\
\hline \multirow{2}{*}{ Moderate or Severe } & $\mathbf{N}$ & 1 & 0 & 1 \\
\hline & $\%$ & $6.7 \%$ & $.0 \%$ & $3.1 \%$ \\
\hline \multirow{2}{*}{ Total } & $\mathbf{N}$ & 15 & 17 & 32 \\
\hline & $\%$ & $100.0 \%$ & $100.0 \%$ & $100.0 \%$ \\
\hline \multirow{2}{*}{ Chi-square } & 1.920 & & & \\
\hline & 0.383 & & & \\
\hline
\end{tabular}

Non-significant difference between responding and non-responding groups post LNF according to Radiological reflux.

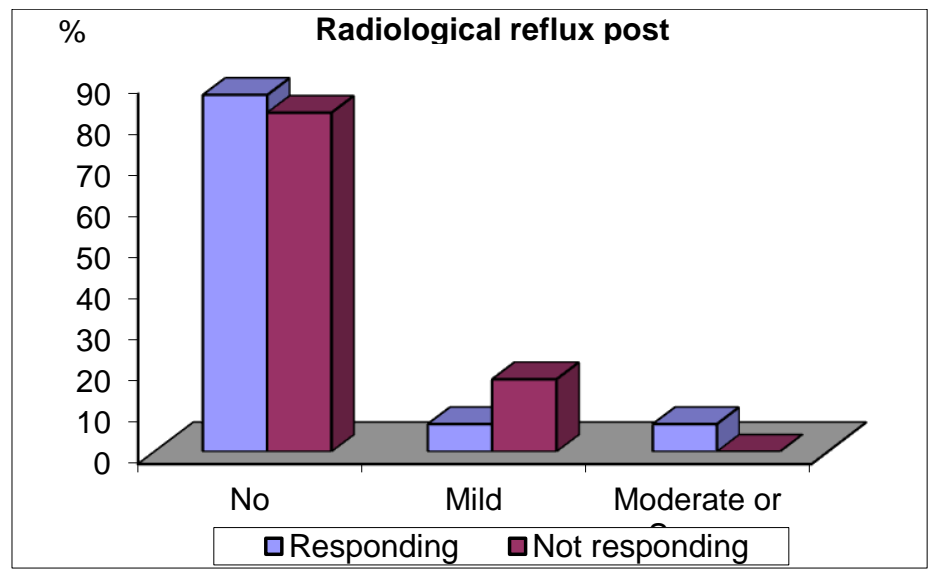

Fig. (19) Comparison between responding and non-responding groups post LNF according to Radiological reflux. Regarding wrap evaluation post LNF by barium study for 32 patient we found 5 patients of them disrupted and 3 migrated up in non-responding group, but 1 tight and 2 migrated up in responding group. The other 21 patient were intact.

Significant difference between responding and non-responding to PPIs cases according to Wrap evaluation. 
Table (20) Wrap evaluation Comparison between responding and non-responding groups post LNF.

\begin{tabular}{|c|c|c|c|c|c|}
\hline \multicolumn{3}{|c|}{ Wrap evaluation } & Responding & Not responding & Total \\
\hline \multirow{2}{*}{\multicolumn{2}{|c|}{ Intact }} & $\mathbf{N}$ & 12 & 9 & 21 \\
\hline & & $\%$ & $80.0 \%$ & $52.9 \%$ & $65.6 \%$ \\
\hline \multirow{2}{*}{\multicolumn{2}{|c|}{ Migrated up }} & $\mathbf{N}$ & 2 & 3 & 5 \\
\hline & & $\%$ & $13.3 \%$ & $17.6 \%$ & $15.6 \%$ \\
\hline \multicolumn{2}{|l|}{ Tight } & $\begin{array}{l}\mathrm{N} \\
\%\end{array}$ & $6.7 \%$ & $\begin{array}{c}0 \\
.0 \%\end{array}$ & $3.1 \%$ \\
\hline \multicolumn{2}{|l|}{ Disrupted } & $\begin{array}{l}\mathbf{N} \\
\%\end{array}$ & $\begin{array}{c}0 \\
.0 \%\end{array}$ & $\begin{array}{c}5 \\
29.4 \%\end{array}$ & $\begin{array}{c}5 \\
15.6 \%\end{array}$ \\
\hline \multicolumn{2}{|l|}{ Total } & $\begin{array}{l}\mathbf{N} \\
\%\end{array}$ & $\begin{array}{c}15 \\
100.0 \%\end{array}$ & $\begin{array}{c}17 \\
100.0 \%\end{array}$ & $\begin{array}{c}32 \\
100.0 \%\end{array}$ \\
\hline Chi-square & $\begin{array}{l}X^{2} \\
\text { P-value }\end{array}$ & $\begin{array}{l}7.519 \\
0.046 *\end{array}$ & & & \\
\hline
\end{tabular}

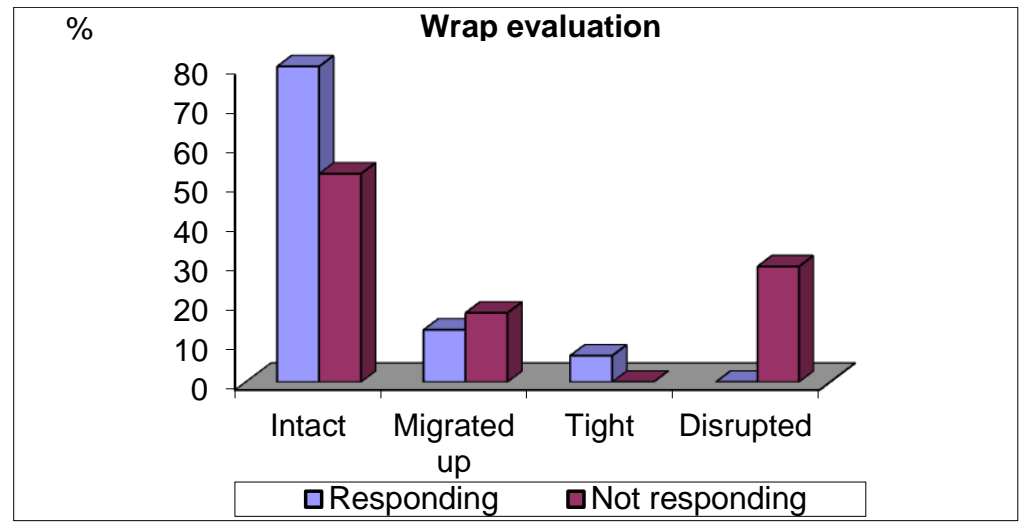

Fig. (20) Wrap evaluation Comparison between responding and non-responding groups post LNF.

Regarding functional assessment of LNF in PPI non-responders, the mean LESP increase from $10.41 \pm 4.79 \mathrm{mmHg}$ before surgery to $20.20 \pm 3.86 \mathrm{mmHg}$ after surgery. Also, the mean LESP in PPI responders increase from $12.72 \pm 4.03$ mmhg before surgery to $20.86 \pm 2.82$ after surgery.

Non-significant difference between responding and non-responding groups according to LESP post LNF.

Table (21) Comparison between responding and non-responding to PPIs cases according to LESP post

\begin{tabular}{|c|c|c|}
\hline LESP post & Responding & Not responding \\
\hline Range & $15.6-24.6$ & $14.5-28.1$ \\
\hline Mean \pm SD & $20.86 \pm 2.82$ & $20.20 \pm 3.86$ \\
\hline T. test & & \\
\hline P. value & & \\
\hline
\end{tabular}

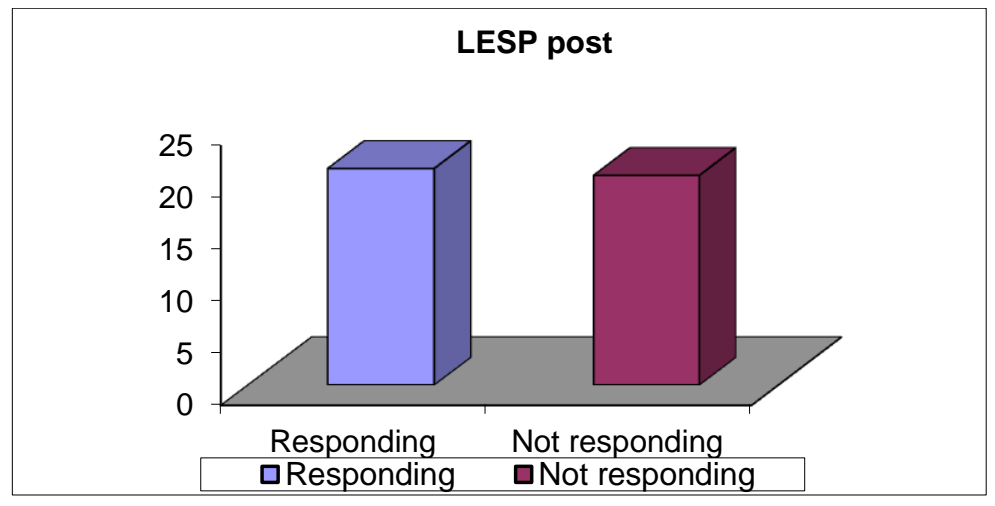

Fig. (21) Comparison between responding and non-responding groups according to LESP post LNF.

Regarding LESR study follow up after LNF there is significant difference in both GERD groups as the mean LESR was $(97.60 \pm 2.73)$ in PPI responders and $(95.20 \pm 1.90)$ in PPI non responders.

Significant difference between responding and non-responding to PPIs cases according to LESR post 
Table (22) Comparison between responding and non-responding groups according to LESR post LNF.

\begin{tabular}{|c|c|c|}
\hline LESR post & Responding & Not responding \\
\hline Range & $90.4-101.3$ & $92.3-99.8$ \\
\hline Mean \pm SD & $97.60 \pm 2.73$ & $95.20 \pm 1.90$ \\
\hline T. test & & \\
\hline
\end{tabular}

Regarding preoperative functional assessment of total time reflux in both groups there is no significant difference as it was $10.58 \pm 1.91$ in PPI responders and $9.79 \pm 1.68$ in PPI non responders.

Table (23) Comparison between responding and non-responding groups according to 24-h pH monitoring preoperative.

\begin{tabular}{llcccc}
\hline 24-h pH monitoring pre & Responding & Not responding & T. test & P. value \\
\hline \multirow{2}{*}{ TR time } & Range & $8.10-14.60$ & $6.20-12.30$ & \multirow{2}{*}{1.397} & 0.170 \\
\multirow{2}{*}{ DM score } & Mean \pm SD & $10.58 \pm 1.91$ & $9.79 \pm 1.68$ & & \\
& Range & $10.90-50$ & $12.50-53.20$ & 1.072 & 0.291 \\
\hline
\end{tabular}

The mean percentage of total reflux time decreased from $(10.58 \pm 1.91)$ before surgery to $(0.96 \pm 0.17)$ after surgery in PPI responders. Also decreased from $(9.79 \pm 1.68)$ before surgery to $(0.88 \pm 0.15)$ after in PPI non responders.

Table (24) Comparison between responding and non-responding groups according to 24-h $\mathrm{pH}$ monitoring postoperative

\begin{tabular}{llcccc}
\hline 24-h pH monitoring post & Responding & Not responding & T. test & P. value \\
\hline \multirow{2}{*}{ TR time } & Range & $0.70-1.20$ & $0.6-1.1$ & \multirow{2}{*}{1.491} & 0.144 \\
& Mean \pm SD & $0.96 \pm 0.17$ & $0.88 \pm 0.15$ & & \\
\multirow{2}{*}{ DM score } & Range & $2-9$ & $2-8$ & \multirow{2}{*}{1.253} & 0.218 \\
& Mean \pm SD & $5.55 \pm 2.08$ & $4.80 \pm 1.68$ & & \\
\hline
\end{tabular}

\section{Discussion}

This study was carried out to evaluate laparoscopic Nissen fundoplication in non-responder patients to medical treatment. At the same time, we compared our results with that obtained from other researches carried out on the same subject.

The Nissen fundoplication is the most commonly performed procedure because it is the easiest to reproduce and adheres to all the principles of an effective anti-reflux procedure, our results are consistent with other published reports demonstrating the efficacy of laparoscopic Nissen fundoplication in eradicating GERD symptoms completely [11].

In our study, the age of patients ranged between 18-50 years with a mean age of 31 years. those responding to medical treatment were 20 patients $(50 \%)$, and those not responding to medical treatment were 20 patients $(50 \%)$, and the male to female ratio was about 1: 1.7 (15:25 in number). Smoking and increased BMI were the main clinical risk factors for GERD with $42.5 \%$ (17 patient) and 40\% (16 patient) respectively [12] assures that smoking and obesity were clinical risk factors associated with GERD in his study.

In the present study, the most common complaint was heartburn in

37 patients $(92.5 \%)$ we also observed regurgitation in 35 patients $(87.5 \%)$, dysphagia in 12 patients $(30 \%)$.
[13] Who showed that heart burn and regurgitation were the most common symptoms in GERD patients.

In a 1-year follow-up, we found a significant decrease in mean symptom scores: for example, heartburn decreased from $92.5 \%$ to $30 \%$, regurgitation from $88.5 \%$ to $17.5 \%$, and dysphagia from $30 \%$ to $12.5 \%[14,15,11]$ observed significant improvement in these common symptoms.

However, in the present study, patients with atypical symptoms of GERD also showed good resolution of symptoms after laparoscopic nissen fundoplication, The reported response of patients with atypical reflux symptoms to $\mathrm{LNF}$ reached up to 64 $\%$.in responding $66 \%$, and $63 \%$ in non-responding, coincided with [16].

The results of this study also support the findings of Brown et al., who described a good response to laparoscopic Nissen fundoplication in GERD patients with atypical symptoms after judicious evaluation and proper patient choice $[17,12]$.

The presented study suggests that surgery (LNF) can elicit a further normalization of acid exposure in PPI responders and partial responders, with a corresponding clinical improvement These data would therefore suggest that in these patients it may be important to further minimize acid exposition regarding 24 ph monitoring in order to attain symptom control. As shown in [18] study. 
The present study indicates that a $\mathrm{pH}$ study is necessary to diagnose persistent or recurrent gastroesophageal reflux in patients who have undergone anti-reflux surgery. Symptoms were not a reliable guide to the presence of abnormal reflux [19, $20]$ assuring that ph study is reliable tool in estimation of post LNF reflux [21].

Regarding functional assessment of LNF in PPI non-responders, the mean LESP increase from $10.41 \pm$ $4.79 \mathrm{mmHg}$ before surgery to $20.20 \pm 3.86 \mathrm{mmHg}$ after surgery. Also, the mean LESP in ppi responders increase from $12.72 \pm 4.03 \mathrm{mmhg}$ before surgery to $20.86 \pm 2.82$ after surgery. [22], [23] and [11] reported that reflux es0phagitis associated with hypotensive LESP and LNF increase LESP in poorly responsive patients to ppi.

We found LNF improves QoL according to reflux symptoms scores, with clear benefit in responding group in comparison to partial responding group. For example, the definition of a partial response to PPI treatment in patients with GERD was often unclear and inconsistent across studies, although this is not surprising given that no consensus definition exists. But the effect of LNF in non-responding is better than medical therapy [24] showed that LNF associated with high degree QoL in responding patients than poorly responding to medical therapy.

In our present series, 20 patients $(50 \%)$ were PPIresistant. Preoperatively, the QoL of these PPI-resistant patients was lower than that of patients with an 'ideal' indication for surgery. However, although their QoL was improved one years after Nissen fundoplication, it remained lower than that of the 'ideal' population [25]. QoL post LNF in PPI resistant patients was lower than good responding patients in 6 years follow up.

Regardless, it is clear that a substantial proportion of partial responders exhibit GERD symptoms one years after LNF, The data presented provide strong evidence that LNF is superior to acid suppressive medication at reducing reflux symptoms in partial responders to PPI therapy [26] assuring that LNF is superior in poor responding than medical therapy.

The reported incidence of early postoperative dysphagia varies; however, most patients will usually complain of some dysphagia in the first few weeks after surgery. Late dysphagia, mostly mild and infrequent, is reported in $5(12.5 \%)$ post LNF out of 12 $(30 \%)$ cases preoperative. This can usually be easily treated with esophageal dilatation and rarely will result in the need for reoperation [27].

In our study "Gas bloat" syndrome is probably due to the trapping of gas in the stomach and small bowel by the competent anti-reflux barrier at the cardio esophageal junction. These patients may have learned to repeatedly swallow saliva and air before surgery in an attempt to clear the esophagus of refluxed gastric acid. This habit may persist into the postoperative period resulting in aerophagia. This syndrome can be difficult to treat and may be troublesome to some patients. [28] reported incidence of gas bloat syndrome, may associated Other symptoms include persistent diarrhea, which may be due to inadvertent vagotomy or the induction of rapid gastric emptying by the fundoplication, chest pain, bloating and belching.

In our study we did not apply the use of proton pump inhibitors (PPI) after LNF as strong indicator of recurrent reflux. Also [11] believed that post LNF use of PPIS was not a strong indicator for reflux recurrence.

None of our patients developed esophageal perforation OR conversion to open surgery considered in any patient. Also [29] had no esophageal perforation or conversion to open.

\section{Conclusion}

Laparoscopic Nissen fundoplication is a safe and effective procedure for gastro-esophageal reflux disease. With experience, the duration of operation falls and the hospital stay is shorter. Short- term symptomatic and $\mathrm{pH}$ results are consistently improved by surgery. It was found that GERD can be treated, with good results, by laparoscopic Nissen fundoplication when medical treatment fails. The procedure can be performed effectively and safely locally.

\section{References}

[1] SD.Peter, \& GW.Holcomb. Gastroesophageal reflux disease and fundoplication in infants and children. Annals of Pediatric Surgery, vol. 3, pp. 1207, 2007.

[2] S.Mehta, J.Bennett, D.Mahon, M.Rhodes. Prospective trial of laparoscopic nissen fundoplication versus proton pump inhibitor therapy for gastroesophageal reflux disease: Seven-year follow-up. J Gastrointest Surg, vol. 10, pp.1312-6, 2006.

[3] M.Anvari, C.Allen, J.Marshall, D.Armstrong, R.Goeree, W.Ungar, C.A.Goldsmith .randomized controlled trial of laparoscopic Nissen fundoplication versus proton pump inhibitors for the treatment of patients with chronic gastroesophageal reflux disease (GERD): 3-year outcomes. Surg Endosc, vol. 25, pp. 2547-54, 2011.

[4] CT.Ferreira, Ed.Carvalho, VL.Sdepanian, MB.Morais, MC.Vieira, LR.Silva. Gastroesophageal reflux disease: exaggerations, evidence and clinical practice. J Pediatr (Rio J), vol. 90, pp.105-18, 2014.

[5] C.Engström, W.Cai, T.Irvine, PG.Devitt, SK.Thompson, PA.Game \& D. I. Watson. Twenty years of experience with laparoscopic antireflux surgery. Journal of British Surgery, vol. 99, pp.1415-1421, 2012.

[6] N.Omura, H.Kashiwagi, F.Yano, K.Tsuboi, Y.Ishibashi, N.Kawasaki, Y.Suzuki, N. Mitsumori, M.Urashima, K.Yanaga. Prediction of recurrence after laparoscopic fundoplication for erosive reflux esophagitis based on anatomy- 
function-pathology (AFP) classification. Surg Endosc. vol. 21, pp.427-30, 2007.

[7] J.Kobiela, Ł.Kaska, M.Pindel, A.Szarmach, M.Janiak, M.Proczko-Markuszewska, T. Stefaniak, D.Łaski, A. Łachiński, Z. Śledziński. Dynamics of quality of life improvement after floppy Nissen fundoplication for gastroesophageal reflux disease. Wideochir Inne Tech Maloinwazyjne, vol. 10, pp.389-97, 2015.

[8] S.Fukahori, M.Yagi, S.Ishii, K.Asagiri, N.Saikusa, N.Hashizume, M.Yoshida, D.Masui, S. Sakamoto, S.Tsuruhisa, T.Kurahachi, Y.Tanaka. Laparoscopic Nissen fundoplication mainly reduces the volume of acid reflux and potentially improves mucosal integrity up to the middle esophagus in neurologically impaired children detected by esophageal combined $\mathrm{pH}$ multichannel intraluminal impedance measurements. J Pediatr Surg, vol. 51, pp.1283-7, 2016.

[9] TD.Kane, MF.Brown, MK.Chen. Members of the APSA New Technology Committee. Position paper on laparoscopic antireflux operations in infants and children for gastroesophageal reflux disease. American Pediatric Surgery Association. J Pediatr Surg, vol. 44, pp.1034-40, 2009.

[10]D.Rhee, Y.Zhang, DC.Chang, MA.Arnold, JH.Salazar-Osuna, K.Chrouser, PM. Colombani, F.Abdullah. Population-based comparison of open vs laparoscopic esophagogastric fundoplication in children: application of the Agency for Healthcare Research and Quality pediatric quality indicators. J Pediatr Surg. vol. 46, pp.648-654, 2011.

[11] T.Abdelrahman, A.Latif, DS. Chan, H. Jones, M. Farag, WG. Lewis, T. Havard, X. Escofet. Outcomes after laparoscopic anti-reflux surgery related to obesity: A systematic review and metaanalysis. Int J Surg, vol. 51, pp.76-82, 2018.

[12]E.Hamdy, A. El Nakeeb, H.Hamed, M.El Hemaly, NG.ElHak. Outcome of laparoscopic Nissen fundoplication for gastroesophageal reflux disease in non-responders to proton pump inhibitors. J Gastrointest Surg. vol. 18, pp.155762, 2014.

[13]RR.Pidoto, F.Fama', G.Giacobbe, MA.Gioffre' Florio, A .Cogliandolo. Quality of life and predictors of long-term outcome in patients undergoing open Nissen fundoplication for chronic gastroesophageal reflux. Am J Surg, vol. 191, pp.470-8, 2006.

[14] JM.Remes-Troche, J.Maher, R.Mudipalli, SS.Rao. Altered esophageal sensory-motor function in patients with persistent symptoms after Nissen fundoplication. Am J Surg, vol. 193, pp. 200-5, 2007.

[15] SB.Ross, S.Gal, AF.Teta, K.Luberice, AS.Rosemurgy. Late results after laparoscopic fundoplication denote durable symptomatic relief of gastroesophageal reflux disease. Am J Surg. vol. 206, pp.47-51, 2013.

[16] MJ.D'Alessio, D. Arnaoutakis, N.Giarelli, DV. Villadolid, AS. Rosemurgy. Obesity is not a contraindication to laparoscopic Nissen fundoplication. J Gastrointest Surg, vol. 9, pp. 949-54, 2005.

[17]C. Esposito, A.Saxena, S. Irtan, H. Till, M. Escolino. Laparoscopic Nissen Fundoplication: An Excellent Treatment of GERD-Related Respiratory Symptoms in Children-Results of a Multicentric Study. J Laparoendosc Adv Surg Tech A, vol. 28, pp. 1023-1028, 2018.

[18]J.Mermelstein, A.Chait Mermelstein, MM.Chait. Proton pump inhibitor-refractory gastroesophageal reflux disease: challenges and solutions. Clin Exp Gastroenterol, vol. 21pp.119. 134, 2018.

[19]D.Prassas, A.Krieg, TM. Rolfs, FJ. Schumacher. Long-term outcome of laparoscopic Nissen fundoplication in a regional hospital setting. Int $\mathrm{J}$ Surg. vol. 46, pp.75-78, 2017.

[20] Salminen P. The laparoscopic Nissen fundoplication--a better operation? Surgeon, vol. 7pp.224-7, 2009.

[21] R. Yadlapati, K. DeLay. Proton Pump InhibitorRefractory Gastroesophageal Reflux Disease. Med Clin North Am, vol. 103, pp.15-27, 2019.

[22]A. Brillantino, M. Schettino, F. Torelli, L. Marano, R. Porfidia, G.Reda, M. Grassia, B. Braccio, N. Di Martino. Laparoscopic NissenRossetti fundoplication is a safe and effective treatment for both Acid and bile gastroesophageal reflux in patients poorly responsive to proton pump inhibitor. Surg Innov. vol. 18, pp.387-93, 2011.

[23]DJ Tessier. Medical, surgical, and endoscopic management of gastroesophageal reflux disease. Perm J, vol. 13, pp.30-6, 2009.

[24] SB.Lee, KM.Jeon, BS. Kim, KC .Kim, HY. Jung, YB. Choi. Early experiences of minimally invasive surgery to treat gastroesophageal reflux disease. J Korean Surg Soc, vol. 84, pp.330-7, 2013.

[25]F.Banki, M.Weaver, D.Roife, C.Kaushik, A.Khanna, K.Ochoa, CC.Miller 3rd. Laparoscopic Reoperative Antireflux Surgery Is More Cost-Effective than Open Approach. J Am Coll Surg, vol. 225, pp.235-242, 2017.

[26] O.Ospanov, A.Maleckas, A. Orekeshova. Gastric greater curvature plication combined with Nissen fundoplication in the treatment of gastroesophageal reflux disease and obesity. Medicina (Kaunas), vol. 52, pp.283-290, 2016.

[27]L. Patrick. Gastroesophageal reflux disease (GERD): a review of conventional and alternative treatments. Altern Med Rev, vol. 16, pp.116-33, 2011.

[28] AP. Silva, V. Tercioti-Junior, LR. Lopes, S. Coelho-Neto Jde, L. Bertanha, PR. Rodrigues, 
NA .Andreollo. Laparoscopic antireflux surgery in patients with extra esophageal symptoms related to asthma. Arq Bras Cir Dig, vol. 27, pp.92-5, 2014.

[29] VN. Prachand, \& JC. Alverdy. Gastroesophageal reflux disease and severe obesity: fundoplication or bariatric surgery? World journal of gastroenterology, vol. 16, pp. 3757, 2010. 